\title{
Bioactive Compounds Constituent and Anti-Inflammatory Activity of Natural Rice Bran Oil Produced from Colored and Non- Pigmented Rice in Northern Thailand
}

\author{
Thanawat Pattananandecha ${ }^{1,2}$, Jakkapan Sirithunyalug ${ }^{1,2}$, Busaban Sirithunyalug ${ }^{1,2}$, \\ Kannika Thiankhanithikun ${ }^{1,2}$, Chartchai Khanongnuch ${ }^{3,4}$ and Chalermpong Saenjum ${ }^{1,2,4,{ }^{*}}$ \\ ${ }^{1}$ Department of Pharmaceutical Sciences, Faculty of Pharmacy, Chiang Mai University, Chiang Mai, 50200, \\ Thailand \\ ${ }^{2}$ Cluster of Excellence on Biodiversity based Economics and Society (B.BES-CMU), Chiang Mai University, \\ Chiang Mai, 50200, Thailand \\ ${ }^{3}$ Division of Biotechnology, School of Agro-Industry, Faculty of Agro-Industry, Chiang Mai University, Chiang \\ Mai, 50100, Thailand \\ ${ }^{4}$ Research Center for Multidisciplinary Approaches to Miang, Research Administration Office, Chiang Mai \\ University, Chiang Mai, 50200, Thailand
}

\begin{abstract}
The aims of the study were to measure and compare the content of the bioactive compounds in natural rice bran oils (NRBOs) and investigate for anti-inflammatory activity through inhibition effect on nitric oxide (NO) and inducible nitric oxide synthase (iNOS) in RAW264.7 mouse macrophage cells. NRBOs were prepared from colored and non-pigmented rice in northern Thailand using the cold-press technique. The bioactive compound constituents in NRBOs, including tocotrienols, tocopherols, and y-oryzanol were analyzed by reversed-phase HPLC. Then, antiinflammatory activity was investigated through an inhibition effect on NO and iNOS production induced by combined lipopolysaccharide (LPS)-interferon- $\gamma$ (IFN- $\gamma$ ) in RAW264.7 mouse macrophage cells. The results demonstrated that NRBOs prepared from purple rice, red rice and non-pigmented rice consist of $\delta, \gamma$, and $\alpha$-tocotrienol, $\delta, \beta, \gamma$, and $\alpha-$ tocopherol, and $\gamma$-oryzanol. $\gamma$-Oryzanol, $\gamma$-tocotrienol, and $\gamma$-tocopherol were the major bioactive compounds in NRBOs. NRBOs prepared from purple rice bran exhibited higher concentrations of the bioactive compounds than red rice bran and non-pigmented rice bran, respectively. Khao' Gam Leum-Phua (KGLP) exhibited the highest amount of $\delta$, $y$ and $\alpha-$ tocotrienol, $\delta, \gamma, \beta$ and $\alpha$-tocopherol, and $\gamma$-oryzanol. Interestingly, all NRBOs inhibited NO and iNOS production by LPS/IFN- $y$-stimulated RAW264.7 cells. Additionally, NRBO prepared from KGLP exhibited the highest inhibitory activity on NO and iNOS production. There may a potential use for pigmented NRBOs especially cultivated in mountainous areas which containing high amounts of tocotrienols, tocopherols, and y-oryzanol, as a natural anti-inflammatory active ingredient in nutraceutical and cosmeceutical products.
\end{abstract}

Keywords: Natural rice bran oil, Tocotrienols, Tocopherols, y-Oryzanol, Anti-inflammatory.

\section{INTRODUCTION}

Rice is grown in all provinces of Thailand. Roughly 60 percent of Thailand's population force is engaged in the agricultural sector. Rice bran offers a valuable nutritional advantage because it contains an antioxidant defense system to protect the rice seed from oxidative stress [1, 2]. Rice bran oil (RBO) is a rich source of steryl ferulate esters, commonly referred to as oryzanol. In addition, RBO is a potential source of tocotrienols, tocopherols, and $\beta$-sitosterol [3-5]. Besides white rice, there are other varieties of rice colors such as red, black, or purple. The outer color is defined by the pigments contained in the pericarp (outer bran) and seed coat of the rice kernels. Thai

*Address correspondence to this author at the Department of Pharmaceutical Sciences, Faculty of Pharmacy, Chiang Mai University, Chiang Mai, 50200, Thailand; Tel: +6653944312; Fax: +6653943490;

E-mail: chalermpong.saenjum@gmail.com

ISSN: 2223-3806 / E-ISSN: 1927-5951/19 purple rice cultivars, Khao' Gam (KG) or Khao' Niaw $D a m$, are highly cultivated by ethnic minorities in mountainous areas, at attitudes 500 meters above sea level, with high productivity, especially in the north of Thailand. These minorities use $K G$ as a food source, in holy ceremonies, and in local wisdom when blending traditional medicine for the relief of various symptoms and illnesses. In Thailand, Thai colored rice is popular for health promotion and non-communicable diseases (NCDs) prevention.

Gamma-oryzanol ( $\mathrm{y}$-oryzanol) was considered as a single compound which is present in $\mathrm{RBO}[6,7]$. In 1999 , it was found that $\mathrm{y}$-oryzanol is a combination of ten phytosteryl ferulate esters including; $\beta$-sitosteryl ferulate as the major bioactive constituents, cycloartenyl ferulate, 24-methylenecycloartanyl ferulate and campesteryl ferulate [8]. $y$-Oryzanol has been reported to have many potential health benefits including reducing plasma lipid and lipoprotein

(C) 2019 SET Publisher 
cholesterol, increasing high-density lipoprotein (HDL) cholesterol levels and inhibiting platelet aggregation [6, $9,10]$. Moreover, $y$-oryzanol also has been reported as a potent antioxidant $[6,10,11]$. Vitamin $E$, tocotrienols and tocopherols are fat-soluble compounds which cannot be produced by the body and have to be taken from a food source [12]. These compounds have potentially beneficial effects including antioxidative and antibacterial activities [7, 13]. Total tocotrienols and tocopherols content in rice bran range from 181 to 314 $\mathrm{mg} / \mathrm{kg}$ [14], while total tocotrienols in RBO have been found to be $585 \mathrm{mg} / \mathrm{l}$ [12]. Pengkumsri et al. (2015) [15] reported that RBOs extracted from brown and red rice contain a significantly higher amount of $y$-tocotrienol than ordinary rice. Both tocotrienols and tocopherols are potent natural antioxidants. However, tocotrienols have been reported to exhibit greater antioxidant properties than tocopherols $[16,17]$. They are both also considered to be helpful in the preventing or treatmenting cardiovascular disease, angiogenic disorder and for reducing blood cholesterol $[18,19]$.

Numerous studies have revealed that purple and black rice contain higher amounts of the following bioactive compounds when compared to white rice: anthocyanin, $\mathrm{y}$-oryzanol, and phenolic compounds [2022]. Additionally, it has been reported that pigmented rice bran exhibits more antioxidant activity than non colored rice bran $[23,24]$. The potential health benefits of Thai pigmented RBO are numerous, and it is one of the most important staples of traditional agriculture in Thailand and Southeast Asia.

The present study was carried out to measure and compare the content of bioactive compounds namely tocotrienols, tocopherol, and $\mathrm{Y}$-oryzanol in NRBOs prepared by the cold-press technique. Moreover, in the purple rice group research was carried out to measure and compare the content of the bioactive compounds between two cultivated rice types: one from a mountainous areas and one from the plains. Furthermore, anti-inflammatory activity through inhibition effect on nitric oxide (NO) and inducible nitric oxide synthase (iNOS) in RAW264.6 cells was also investigated. Current results may establish the health benefits of NRBOs and to support the use of NRBOs as a natural anti-inflammatory active ingredient for nutraceutical or cosmeceutical products.

\section{MATERIALS AND METHODS}

\section{Materials}

Tocotrienols, tocopherols, and $\mathrm{y}$-oryzanol were purchased from Wako Pure Chemical Industries
(Japan). Curcumin and quercetin were purchased from Tokyo Chemical Industries Co., Ltd. (Japan). All solvents and chemicals used (analytical or HPLC grade) were obtained from Sigma Chemical Co., Ltd. (St. Louis, MO) and Merck (Darmstadt, Germany). Additionally, all solvents and chemicals used in the cellbased study were obtained from Invitrogen ${ }^{\text {TM }}$ (USA) and Roche (Germany). RAW264.7 mouse macrophage cell line was purchased from American Cell Culture Collection (Bethesda, MD, USA) and mouse iNOS immunoassay was purchased from MyBioSource, USA Inc. (USA).

\section{Methods}

\section{Preparation of NRBOs}

Eleven native rice cultivars with different colors were harvested from a rice research center in Northern Thailand. The purple rice group namely Khao' Gam Boung (KGB), Khao' Gam Thor (KGT), Khao' Gam Leum-Phua (KGLP), Khao' Gam Pha Yao (KGPY) and Khao' Gam Chiang Rai (KGCR), the red rice group namely Khao' Hom Dang Sukhothai 1 (KHDS1), Khao' Tubtim Chum Phae and Khao' Hom Mali Dang (KHMLD) and the non-colored rice group namely Khao' Dawk Mali 105 (KDML), RD6 and Khao' Niew San-pahtawng (KNSPT) were dried in a hot air oven at $60{ }^{\circ} \mathrm{C}$ for $48 \mathrm{~h}$. The purple rice samples were collected from two different geographic areas. Group I: KGB, KGT, and KGLP were cultivated in the mountainous areas. Group II including KGPY, KGCR, red rice, and noncolored rice samples were grown on the plains. Rice samples were milled using a rice milling machine (Thongtawee, Thailand, Model: NW 1000 TURBO) to obtain fresh rice bran, then sieved through a 20-mesh sieve. Subsequently, all of the rice bran samples were stabilized by a heating-cooling process to inactivate endogenous lipase [25], and all NRBO samples were then prepared using a cold-press technique (Friend Energy Limited Partnership, Thailand, Model: 2013).

\section{Determination of $y$-Oryzanol Content by Reversed- Phase HPLC}

The y-oryzanol content in NRBO samples was determined using the method of Sirithunyalug et al. [26]. Briefly, the analysis method was conducted using Agilent 1200 connected with a UV detector set at 330 $\mathrm{nm}$. Methanol, acetonitrile, dichloromethane, and acetic acid were used as the mobile phase in the ratio of $50: 44: 3: 3$ at the flow rate of $1.0 \mathrm{ml} / \mathrm{min}$. The Symmetry Shield RP18 column $(250 \times 4.6 \mathrm{~mm}, 5 \mu \mathrm{m}$, Water Co., Ltd., USA) was used and all samples were measured in triplicate. 
Determination of $\delta, \beta, \gamma$ and $\alpha$-Tocotrienol, $\delta, \beta, \gamma$ and $\alpha$-Tocopherol Content by Reversed-Phase HPLC

Eight forms of both tocotrienols and tocopherols in NRBO samples were determined using the method of Sirithunyalug et al. [26]. Briefly, the analysis method was conducted using an Agilent 1200 coupled with a fluorescence detector. The KINETEX PFP column (150 x $4.6 \mathrm{~mm}, 2.6 \mu \mathrm{m}$ ) was used (Phenomenex Co, Ltd., USA). Methanol and water were used as the mobile phase in a ratio of $9: 1$ at a flow rate of $0.6 \mathrm{ml} / \mathrm{min}$. The excitation and the emission wavelength of the detector were set at $292 \mathrm{~nm}$ and $330 \mathrm{~nm}$, respectively. All samples were analyzed in triplicate.

\section{Anti-inflammatory Activity Determination through Inhibition on NO and iNOS Production}

The inhibition of $\mathrm{NO}$ and iNOS production were determined using a modified version of the method of Sirithunyalug et al. [26] and Tuntipopipat et al. [27]. RAW264.7 murine macrophage cells were grown in Dulbecco's Modified Eagle's Medium (DMEM) supplemented with $10 \%$ fetal bovine serum (FBS), 100 units $/ \mathrm{ml}$ penicillin and $100 \mu \mathrm{g} / \mathrm{ml}$ streptomycin. After 24 $\mathrm{h}$ of pre-incubation in 24-well plates, RAW264.7 cells were replaced with fresh medium containing different concentrations of the tested samples at the concentration of $10,25,50$, and $100 \mu \mathrm{g} / \mathrm{ml}$ and incubated for $12 \mathrm{~h}$. Then interferon- $\mathrm{\gamma}$ (IFN- $\mathrm{\gamma}$ ) and lipopolysaccharide (LPS) were added in the concentration of $50 \mathrm{pg} / \mathrm{ml}$ and $2 \mathrm{ng} / \mathrm{ml}$, respectively and incubated for $72 \mathrm{~h}$. The culture medium was collected to be measured for NO content, and the cells were lysed using CelLytic ${ }^{\mathrm{TM}} \mathrm{M}$ Cell Lysis Buffer (Sigma, C2978) to assay for iNOS. The level of nitrite, a stable form of NO, was spectrometrically analyzed using Griess reagent at $540 \mathrm{~nm}$. The level of iNOS production in the cell lysates was measured using mouse iNOS ELISA kit. Curcumin, y-oryzanol, $Y$ tocotrienol, and $Y$-tocopherol were used as positive controls. The amount of DNA was quantified by the Quant-iT PicoGreen Assay (Invitrogen, P11496) according to the manufacturer's protocol. The level of protein produced by RAW 264.7 cells was measured using Bradford reagent (Bio-Rad, USA). The viability of RAW264.7 cells was investigated using cell

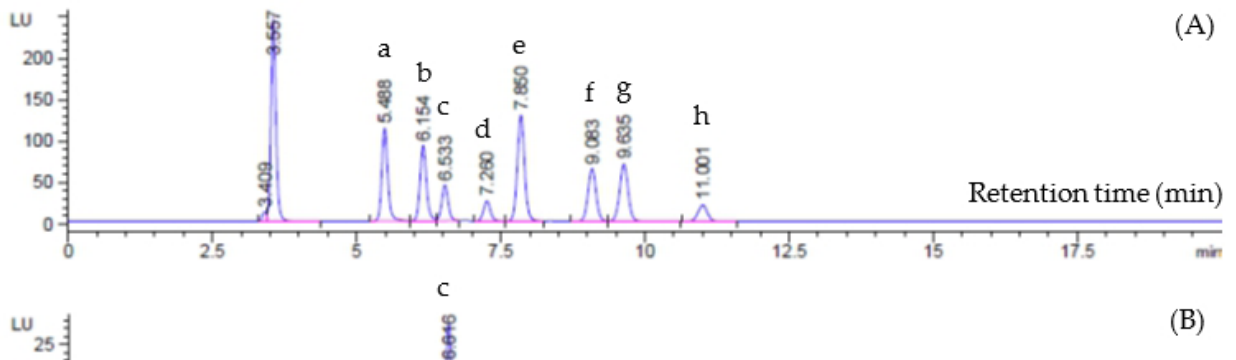

(A)
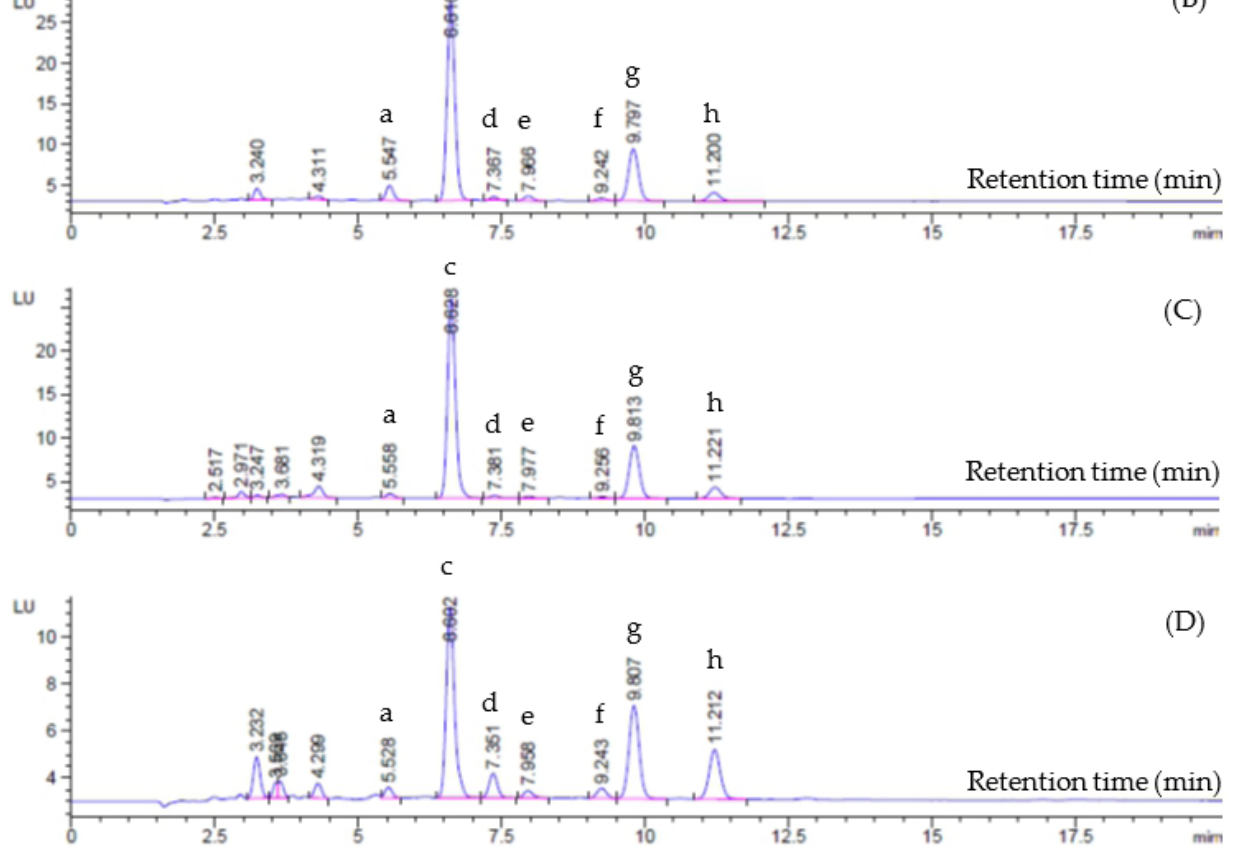

Figure 1: HPLC chromatogram of reference tocotrienols, tocopherols, and natural rice bran oils (NRBOs). (A) Mixed reference tocotrienols and tocopherols, including $\delta$-tocotrienol (a), $\beta$-tocotrienol (b), $\gamma$-tocotrienol (c), $\alpha$-tocotrienol (d), $\delta$-tocopherol (e), $\beta$ tocopherol (f), y-tocopherol (g), and $\alpha$-tocopherol (h); and NRBOs including (B) KGLP, (C) KHDS1 and (D) KNSPT. 
proliferation reagent WST-1 following the methods of Sirithunyalug et al. [26] and Jomha et al. [28].

\section{Statistical Analysis}

Current results were expressed as a mean of three replicate \pm standard deviations (SD). SPSS (version 16) was used for statistical analysis. $P$ values $<0.05$ were considered to be significant.

\section{RESULTS}

Determination of the $\delta, \beta, y$ and $\alpha$-Tocotrienol, $\delta, \beta$, $\gamma$ and $\alpha$-Tocopherol, and $y$-Oryzanol Contents

The amount of $\delta, \beta, \gamma$ and $\alpha$-tocotrienol, $\delta, \beta, \gamma$ and $\alpha$-tocopherol and $\gamma$-oryzanol contents in rice bran oils from different-colored rice namely purple rice, red rice, and non-colored rice were determined. The HPLC chromatogram of reference tocotrienols, tocopherols, and NRBOs are shown in Figure 1 and the HPLC chromatogram of reference $\mathrm{y}$-oryzanol and NRBOs are shown in Figure 2, respectively.

The amounts of all components are shown in Table 1-3. $\beta$-tocotrienol was undetectable in all NRBOs. All of NRBOs comprised of 4 major components of $\mathrm{y}$ - oryzanol including cycloartenyl ferulate, 24methylenecycloartanyl ferulate, campesteryl ferulate, and $\beta$-sitosteryl ferulate. NBO prepared from KGLP exerted the highest amount of $\delta, \gamma$ and $\alpha$-tocotrienol and $\delta, \gamma, \beta$ and $\alpha$-tocopherol, and $\gamma$-oryzanol. KGB and KGT were found to have a high content of the compounds.

\section{Anti-inflammatory Activity of Rice Bran Oils on NO and iNOS Inhibition}

The anti-inflammatory activity of NRBOs was investigated through their inhibitory effects on $\mathrm{NO}$ and iNOS production in LPS/IFN- $\gamma$ induced RAW264.7 cells. NRBOs significantly inhibited the LPS/IFN-Ymediated induction of $\mathrm{NO}$ and iNOS production compared to the positive controls namely $\mathrm{Y}$-oryzanol, $\mathrm{Y}$ tocotrienol, $\mathrm{Y}$-tocopherol and curcumin as shown in Table 4. The NRBO prepared from KGLP demonstrated the most potent inhibitory effect on NO production. Both NRBOs prepared from KGLP and KGB exhibited the highest inhibitory activity on iNOS production. All of NRBOs inhibited $\mathrm{NO}$ and iNOS production by LPS/IFN-y-induced RAW264.7 cells without the presence of cytotoxicity to RAW264.7 cells at concentrations lower than $100 \mu \mathrm{g} / \mathrm{ml}$. $50 \%$
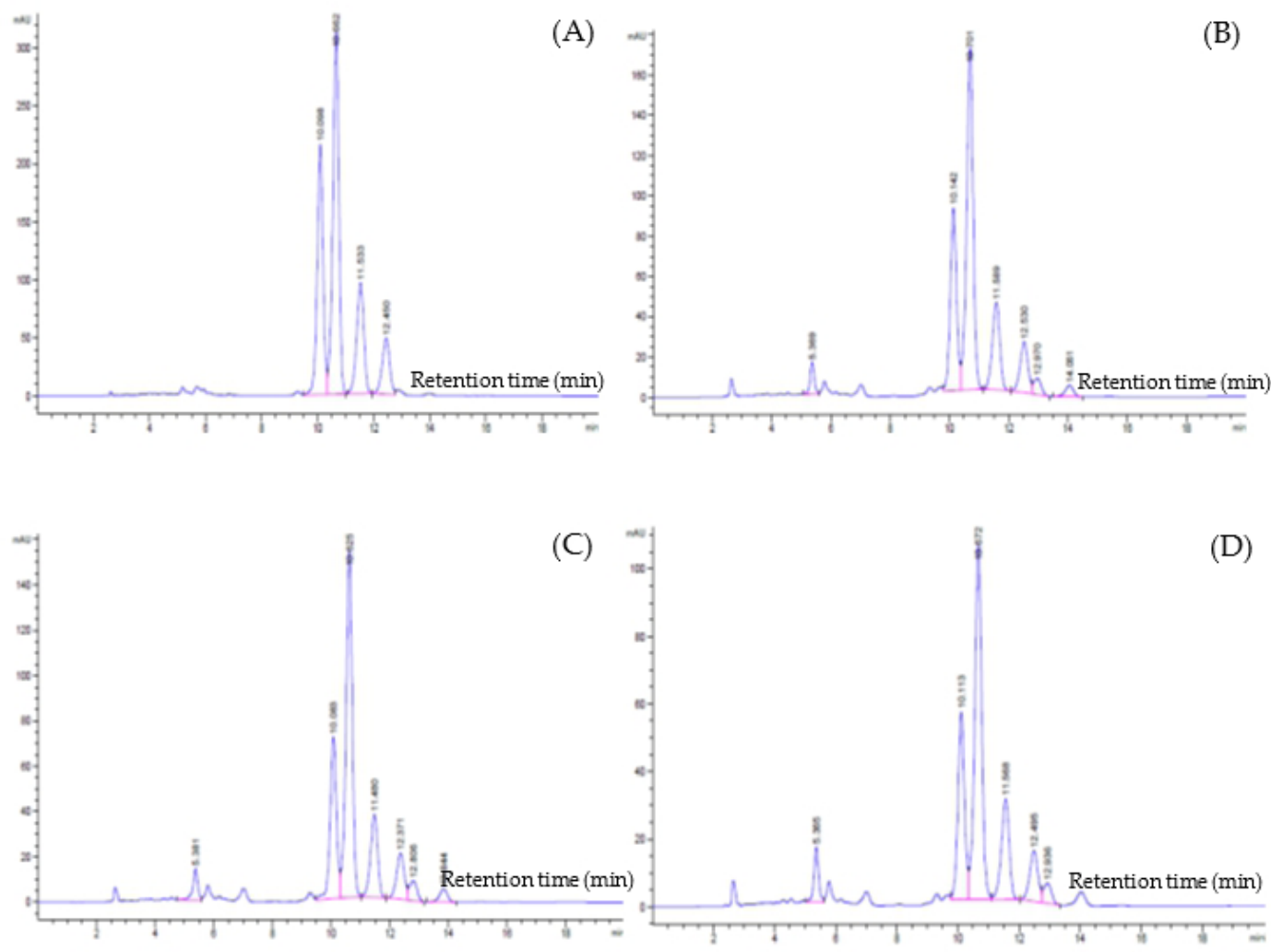

Figure 2: HPLC chromatogram of reference $\mathrm{Y}$-oryzanol and natural rice bran oils (NRBOs). (A) Reference $\mathrm{Y}$-oryzanol and NRBOs including (B) KGLP, (C) KHDS1 and (D) KNSPT. 
Table 1: Tocotrienol Contents in Rice Bran Oils

\begin{tabular}{|c|c|c|c|}
\hline Samples & \multicolumn{3}{|c|}{ Components (mg/g) } \\
\hline Khao' Gam Boung (KGB) & $0.13 \pm 0.01^{b}$ & $1.63 \pm 0.08^{b}$ & $0.22 \pm 0.02^{b}$ \\
\hline Khao' Gam Thor (KGT) & $0.12 \pm 0.01^{\mathrm{bc}}$ & $1.59 \pm 0.06^{b}$ & $0.20 \pm 0.02^{\mathrm{bc}}$ \\
\hline Khao' Gam Leum-Phua (KGLP) & $0.15 \pm 0.02^{\mathrm{a}}$ & $1.74 \pm 0.07^{\mathrm{a}}$ & $0.26 \pm 0.02^{\mathrm{a}}$ \\
\hline Khao' Hom Dang Sukhothai 1 (KHDS1) & $0.09 \pm 0.01^{\mathrm{d}}$ & $1.35 \pm 0.06^{\mathrm{d}}$ & $0.16 \pm 0.01^{\mathrm{ef}}$ \\
\hline Khao' Tubtim Chum Phae (KTTCP) & $0.11 \pm 0.01^{\text {cd }}$ & $1.42 \pm 0.05^{\mathrm{cd}}$ & $0.17 \pm 0.01^{\text {def }}$ \\
\hline Khao' Hom Mali Dang (KNR) & $0.07 \pm 0.01^{\mathrm{e}}$ & $1.09 \pm 0.08^{\mathrm{e}}$ & $0.14 \pm 0.01^{f}$ \\
\hline Khao' Dawk Mali 105 (KDML) & $0.03 \pm 0.01^{f}$ & $0.59 \pm 0.05^{f}$ & $0.07 \pm 0.01^{\mathrm{h}}$ \\
\hline
\end{tabular}

*Data are presented as mean $\pm \mathrm{SD}$; triplicates; $\mathrm{n}=3$ Mean values within a column superscripted by the same letter are not significantly different at $P<0.05$.

Table 2: Tocopherol Contents in Rice Bran Oils

\begin{tabular}{|c|c|c|c|c|}
\hline \multirow{2}{*}{ Samples } & \multicolumn{4}{|c|}{ Components (mg/g) } \\
\hline & ס-tocopherol & V-tocopherol & $\alpha$-tocopherol & $\beta$-tocopherol \\
\hline Khao' Gam Boung (KGB) & $0.11 \pm 0.01^{\mathrm{bc}}$ & $1.35 \pm 0.04^{\mathrm{ab}}$ & $0.46 \pm 0.03^{b}$ & $0.14 \pm 0.01^{b}$ \\
\hline Khao' Gam Leum-Phua (KGLP) & $0.15 \pm 0.01^{\mathrm{a}}$ & $1.42 \pm 0.06^{\mathrm{a}}$ & $0.54 \pm 0.03^{\mathrm{a}}$ & $0.16 \pm 0.01^{\mathrm{a}}$ \\
\hline Khao' Gam Pha Yao (KGPY) & $0.09 \pm 0.01^{\text {de }}$ & $0.98 \pm 0.06^{\text {cd }}$ & $0.36 \pm 0.03^{d}$ & $0.11 \pm 0.01^{c}$ \\
\hline Khao' Tubtim Chum Phae (KTTCP) & $0.09 \pm 0.01^{\text {de }}$ & $1.04 \pm 0.06^{c}$ & $0.34 \pm 0.02^{\mathrm{de}}$ & $0.10 \pm 0.01^{c}$ \\
\hline Khao' Hom Mali Dang (KNR) & $0.06 \pm 0.01^{f}$ & $0.80 \pm 0.05^{\mathrm{e}}$ & $0.27 \pm 0.03^{\mathrm{fg}}$ & $0.07 \pm 0.01^{\mathrm{e}}$ \\
\hline Khao' Dawk Mali 105 (KDML) & $0.02 \pm 0.01^{g}$ & $0.36 \pm 0.04^{9}$ & $0.18 \pm 0.02^{i}$ & $0.03 \pm 0.00^{f}$ \\
\hline$R D 6$ & $0.03 \pm 0.01^{g}$ & $0.37 \pm 0.03^{9}$ & $0.23 \pm 0.03^{\mathrm{gh}}$ & $0.05 \pm 0.01^{\mathrm{e}}$ \\
\hline
\end{tabular}

*Data are presented as mean $\pm \mathrm{SD}$; triplicates; $\mathrm{n}=3$ Mean values within a column superscripted by the same letter are not significantly different at $P<0.05$.

Table 3: y-Oryzanol Contents in Rice Bran Oils

\begin{tabular}{|c|c|}
\hline Samples & Components (mg/g) \\
\cline { 2 - 3 } & v-oryzanol \\
\hline \hline Khao' Gam Boung (KGB) & $66.43 \pm 0.85^{\mathrm{b}}$ \\
\hline Khao' Gam Thor (KGT) & $60.50 \pm 1.27^{\mathrm{c}}$ \\
\hline Khao' Gam Leum-Phua (KGLP) & $78.49 \pm 1.45^{\mathrm{a}}$ \\
\hline Khao' Gam Pha Yao (KGPY) & $47.27 \pm 0.97^{\mathrm{e}}$ \\
\hline Khao' Gam Chiang Rai (KGCR) & $52.72 \pm 1.22^{\mathrm{d}}$ \\
\hline Khao' Hom Dang Sukhothai 1 (KHDS1) & $43.86 \pm 1.10^{f}$ \\
\hline Khao' Tubtim Chum Phae (KTTCP) & $46.33 \pm 1.12^{\mathrm{g}}$ \\
\hline Khao' Hom Mali Dang (KNR) & $40.65 \pm 0.99^{\mathrm{e}}$ \\
\hline Khao' Dawk Mali 105 (KDML) & $33.75 \pm 1.16^{\mathrm{i}}$ \\
\hline RD6 & $36.25 \pm 1.09^{\mathrm{h}}$ \\
\hline Khao' Niew San-pah-tawng (KNSPT) & $34.41 \pm 0.85^{\mathrm{hi}}$ \\
\hline
\end{tabular}

${ }^{*}$ Data are presented as mean $\pm \mathrm{SD}$; triplicates; $\mathrm{n}=3$ Mean values within a column superscripted by the same letter are not significantly different at $P<0.05$. 
Table 4: Anti-Inflammatory Activities of Rice Bran Oils

\begin{tabular}{|c|c|c|}
\hline Samples & \multicolumn{2}{|c|}{$50 \%$ Inhibition Concentration $(\mu \mathrm{g} / \mathrm{ml})$} \\
\hline Khao' Gam Boung (KGB) & $15.92 \pm 0.81^{\mathrm{c}}$ & $19.07 \pm 0.66^{\mathrm{c}}$ \\
\hline Khao' Gam Thor (KGT) & $17.24 \pm 0.95^{\mathrm{c}}$ & $17.27 \pm 0.50^{\mathrm{b}}$ \\
\hline Khao' Gam Leum-Phua (KGLP) & $13.28 \pm 0.78^{b}$ & $16.52 \pm 0.51^{b}$ \\
\hline Khao' Hom Dang Sukhothai 1 (KHDS1) & $28.72 \pm 1.39^{f}$ & $39.62 \pm 0.72^{f}$ \\
\hline Khao' Tubtim Chum Phae (KTTCP) & $26.45 \pm 1.20^{\mathrm{e}}$ & $35.03 \pm 0.85^{\mathrm{e}}$ \\
\hline Khao' Hom Mali Dang (KHMLD) & $31.09 \pm 1.26^{\mathrm{g}}$ & $41.48 \pm 0.89^{9}$ \\
\hline Khao' Dawk Mali 105 (KDML) & $85.42 \pm 1.98^{k}$ & $90.07 \pm 0.84^{j}$ \\
\hline Y-oryzanol & $36.29 \pm 0.88^{h}$ & $38.52 \pm 0.75^{f}$ \\
\hline Y-tocotrienol & $26.65 \pm 0.69^{e}$ & $29.79 \pm 0.51^{d}$ \\
\hline y-tocopherol & $32.33 \pm 0.76^{9}$ & $35.26 \pm 0.55^{\mathrm{e}}$ \\
\hline Curcumin & $8.84 \pm 0.49^{\mathrm{a}}$ & $12.19 \pm 0.43^{\mathrm{a}}$ \\
\hline
\end{tabular}

*Data are presented as mean $\pm \mathrm{SD}$; triplicates; $\mathrm{n}=3$ Mean values within a column superscripted by the same letter are not significantly different at $P<0.05$.

concentration inhibition of all NRBOs in NO and iNOS seem related to the level of tocotrienols, tocopherols, and $y$-oryzanol content. However, the inhibitory effects of all the NRBOs were lower than curcumin, a potent natural anti-inflammatory. Remarkably, the inhibitory activities of all natural purple rice bran oils on NO were higher than $\mathrm{y}$-oryzanol, $\mathrm{y}$-tocotrienol, and $\mathrm{y}$-tocopherol. The inhibitory activities of NRBOs prepared from KGLP, KGT and KGB on iNOS were higher than $\mathrm{Y}$ tocotrienol, $\mathrm{y}$-tocopherol, and $\mathrm{y}$-oryzanol.

\section{DISCUSSION}

NRBO is a rich source of the important compounds tocotrienol, tocopherol and $\mathrm{Y}$-oryzanol, which are considered to protect against degenerative diseases [29]. Interestingly, natural purple rice bran oil (NPRBO) prepared from purple rice samples collected from the mountainous areas (KGB, KGT, and KGLP) contained higher $\mathrm{Y}$-oryzanol, tocotrienols, and tocopherols than that collected from the plains (KGPY and KGCR). Various studies suggest that the efficacy of these compounds on antioxidant activity may differ among sources [12]. The result of this study corresponded with previous reporting by Sirithunyalug et al. [26]. Moreover, NPRBO prepared by cold press technique composed of $\beta$-tocopherol which can-not be detected in NPRBO prepared by supercritical carbon dioxide extraction [26]. RBOs prepared from purple rice bran seem to have higher contents of the compounds than red rice bran and non-colored rice bran. This corresponds to a previous study by Pengkumsri et al. [15] who reported the content of total tocols (tocotrienol and tocopherol), $\mathrm{Y}$-oryzanol and antioxidant properties of black rice, red rice, and brown RBO. Their results demonstrated that RBO extracted from darker pigmented rice bran had higher amounts of the compounds. According to some studies, the antioxidant activity of colored rice is greater than that of noncolored rice [30, 31]. The elevated bioactive properties of colored rice bran give it good potential as a natural active ingredient with positive effects on human health [29].

The non-polar components namely $y$-oryzanol, tocotrienols, and tocopherols are responsible for the anti-inflammatory properties of NRBOs. The lipophilicity of $y$-oryzanol, tocotrienols, and tocopherols may give them the ability to pass through the cell membrane in the cell-based study. Previous studies have found that palm oil has potent anti-inflammatory capabilities due to its being rich in tocotrienols, which inhibit iNOS production and NF-KB expression in human monocytic (THP-1) cells [30]. This corresponds with the results of the current study. Moreover, it has been reported that black rice bran extract has the ability to suppress inflammation symptoms induced by tetradecanolylphorbol acetate (TPA) as well as to 
decrease TNF- $\alpha$, IL-1 $\beta, \mathrm{IL}-6$, and LTB4 production in mouse models [31]. Tocopherols possess apoptosisinducing, anti-inflammatory, antioxidant, and reactive nitrogen species-trapping activities may have contributed to the fact that colon carcinogenesis was found to be inhibited by a $\gamma$-tocopherol-rich mixture (57\% Y-tocopherol, 24\% $\delta$-tocopherol, 13\% $\alpha$ tocopherol) in azoxymethane (AOM)/dextran sulfate sodium (DSS)-treated in animal models [32]. Cold press NRBOs prepared from various rice varieties in Thailand have anti-inflammatory and antioxidant properties, as is shown by the effects of antiinflammatory and antioxidant activity on the inhibition of NO production using RAW267.4 cell lines and antioxidant activities [33]. The unsaponifiable fraction of rice bran and $y$-oryzanol supplemented in the dietary oils exerts a significant role in decreasing the secretion of pro-inflammatory mediators by macrophages in rat models $(60 \mathrm{~d})$ [34]. This is interesting considering that tocotrienols, tocopherols, and $\mathrm{y}$-oryzanol in NRBOs related to their inhibitory effects on NO and iNOS production.

In summary, the NRBOs prepared from purple rice, red rice, and non-colored rice were comprised of $\delta, \gamma$, and $\alpha$-tocotrienol, $\delta, \beta, \gamma$, and $\alpha$-tocopherol, and $\gamma$ oryzanol. NPRBO especially KGLP exhibited the highest content of $\mathrm{Y}$-oryzanol, tocotrienols, and tocopherols. Moreover, it was found that pigmented rice bran in general exhibits higher content of tocotrienols, tocopherols, and $y$-oryzanol than noncolored rice bran (purple rice bran>red rice bran>noncolored rice bran). This study indicated that the NRBOs exhibited potent anti-inflammatory activity in a cellbased study as compared to the positive controls including $\mathrm{Y}$-tocotrienol, $\mathrm{y}$-tocopherol, $\mathrm{Y}$-oryzanol, and curcumin. The NRBOs prepared from purple rice bran, especially KGLP demonstrated the highest inhibitory activity on NO and iNOS production in LPS/IFN- $\gamma-$ induced RAW264.7 cells. The results presented here suggest that there is potential in using pigmented NRBOs containing high amounts of tocotrienols, tocopherols, and $\mathrm{y}$-oryzanol as a natural antiinflammatory active ingredient.

\section{ACKNOWLEDGEMENTS}

Authors would like to acknowledge financial support from the National Research Council of Thailand (NRCT, project number 105878). This work was also supported by Postdoctoral fellowship granted by Chiang Mai University.

\section{REFERENCES}

[1] Law BMH, Waye MMY, So WKW, Chair SY. Hypotheses on the potential of rice bran intake to prevent gastrointestinal cancer through the modulation of oxidative stress. Int $\mathrm{J} \mathrm{Mol}$ Sci 2017; 18: 1352. https://doi.org/10.3390/ijms18071352

[2] Sukrasno S, Tuty S, Fidrianny I. Antioxidant evaluation and phytochemical content of various rice bran extracts of three varieties rice from Semarang-central java, Indonesia. Asian J Pharm Clin Res 2017; 10: 377-82. https://doi.org/10.22159/ajpcr.2017.v10i6.16565

[3] Krager KJ, Pineda EN, Kharade SV, Kordsmeier M, Howard $\mathrm{L}$, Breen PJ, et al. Tocotrienol-Rich Fraction from Rice Bran Demonstrates Potent Radiation Protection Activity. Evid Based Complement Alternat Med 2015; 2015: 148791. https://doi.org/10.1155/2015/148791

[4] Rakha A, Butt MS, lqbal MJ, Rashid S. Rice bran nutraceutics: A comprehensive review AU - Sohail, Muhammad. Crit Rev Food Sci Nutr 2017; 57: 3771-80. https://doi.org/10.1080/10408398.2016.1164120

[5] Chaiyasut C, Kesika P, Sakdakampanat P, Peerajan S, Sivamaruthi BS. Formulation and evaluation of stability of Thai purple rice bran-based cosmetic products. Asian J Pharm Clin Res 2018; 11: 99-104. https://doi.org/10.22159/ajpcr.2018.v11i1.22073

[6] Mingyai S, Kettawan A, Srikaeo K, Singanusong R. Physicochemical and antioxidant properties of rice bran oils produced from colored rice using different extraction methods. J Oleo Sci 2017; 66: 565-72. https://doi.org/10.5650/jos.ess17014

[7] Settharaksa S, Madaka F, Charkree K, Charoenchai L. The study of anti-inflammatory and antioxidant activity in cold press rice bran oil from rice in Thailand. Int $\mathrm{J}$ Pharm Pharm Sci 2014; 6: 428-31.

[8] Pornputtapitak W, Pantakitcharoenkul J, Panpakdee R, Teeranachaideekul V, Sinchaipanid N. Development of gamma-oryzanol rich extract from Leum Pua glutinous rice bran loaded nanostructured lipid carriers for topical delivery. J Oleo Sci 2018; 67: 125-33.

\section{https://doi.org/10.5650/jos.ess 17113}

[9] Bumrungpert A, Chongsuwat R, Phosat C, Butacnum A. Rice bran oil containing gamma-oryzanol improves lipid profiles and antioxidant status in hyperlipidemic subjects: A randomized double-blind controlled trial. J Altern Complement Med 2018, doi: 10.1089/acm.2018.0212. https: //www.liebertpub.com/doi/full/10.1089/acm.2018.0212.

[10] Sivamaruthi B, Kesika P, Chaiyasut C. A comprehensive review on anti-diabetic property of rice bran. Asian Pac $J$ Trop Biomed 2018; 8: 79-84. https://doi.org/10.4103/2221-1691.221142

[11] Minatel IO, Francisqueti FV, Correa CR, Lima GP Antioxidant activity of gamma-oryzanol: a complex network of interactions. Int J Mol Sci 2016; 17(8).

https://doi.org/10.3390/ijms17081107

[12] Ahsan $\mathrm{H}$, Ahad A, Siddiqui WA. A review of characterization of tocotrienols from plant oils and foods. J Chem Biol 2015; 8: 45-59. https://doi.org/10.1007/s12154-014-0127-8

[13] Dasari P, R. A, Nayak P. Effect of tocotrienol pretreatment on ex vivo superoxide and peroxide handling capacities (SPHC) of rat serum and brain. Int J Pharm Pharm Sci 2017; 9: 11622.

https://doi.org/10.22159/ijpps.2017v9i3.15866

[14] Huang SH, Ng LT. Quantification of tocopherols, tocotrienols, and gamma-oryzanol contents and their distribution in some commercial rice varieties in Taiwan. J Agric Food Chem 2011; 59: 11150-9

https://doi.org/10.1021/jf202884p 
[15] Pengkumsri N, Chaiyasut C, Sivamaruthi BS, Saenjum C, Sirilun S, Peerajan $\mathrm{S}$, et al. The influence of extraction methods on composition and antioxidant properties of rice bran oil. Food Sci Technol (Campinas) 2015; 35: 493-501. https://doi.org/10.1590/1678-457X.6730

[16] Serbinova EA, Packer L. Antioxidant properties of alphatocopherol and alpha-tocotrienol. Methods Enzymol 1994; 234: 354-66. https://doi.org/10.1016/0076-6879(94)34105-2

[17] Aggarwal BB, Sundaram C, Prasad S, Kannappan R. Tocotrienols, the vitamin $\mathrm{E}$ of the $21^{\text {st }}$ century: its potential against cancer and other chronic diseases. Biochem Pharmacol 2010; 80: 1613-31. https://doi.org/10.1016/j.bcp.2010.07.043

[18] Hu XX, Fu L, Li Y, Lin ZB, Liu X, Wang JF, et al. The cardioprotective effect of vitamin e (alpha-tocopherol) is strongly related to age and gender in mice. PloS one. 2015; 10: e0137405.

https://doi.org/10.1371/journal.pone.0137405

[19] Waniek S, di Giuseppe R, Esatbeyoglu T, Plachta-Danielzik $\mathrm{S}$, Ratjen I, et al. Vitamin E (alpha- and gamma-Tocopherol) levels in the community: distribution, clinical and biochemical correlates, and association with dietary patterns. Nutrients 2017; 10: 1-17.

https://doi.org/10.3390/nu10010003

[20] Vichit W, Saewan N. Antioxidant activities and cytotoxicity of Thai pigmented rice. Int J Pharm Pharm Sci 2015; 7: 329-34.

[21] Kushwaha UKS. Black rice anthocyanin content increases with increase in altitude of its plantation. Adv Plants Agric Res 2016; 5 469-72. https://doi.org/10.15406/apar.2016.05.00170

[22] Pedro AC, Granato D, Rosso ND. Extraction of anthocyanins and polyphenols from black rice (Oryza sativa L.) by modeling and assessing their reversibility and stability. Food Chem 2016; 191: 12-20.

https://doi.org/10.1016/j.foodchem.2015.02.045

[23] Muntana N, Prasong S. Study on total phenolic contents and their antioxidant activities of Thai white, red and black rice bran extracts. Pak J Biol Sci 2010; 13: 170-4. https://doi.org/10.3923/pjbs.2010.170.174

[24] Sompong R, Siebenhandl-Ehn S, Linsberger-Martin G, Berghofer E. Phytochemical and antioxidative properties of red and black rice varieties from Thailand, China and Sri Lanka. Food Chem 2011; 124: 132-40. https://doi.org/10.1016/j.foodchem.2010.05.115
[25] Malekian F. Lipase and lipoxygenase activity, functionality, and nutrient losses in rice bran during storage. LSU Agricultural Experiment Station Reports. 293: LA, USA, 2000.

[26] Sirithunyalug B, Saenjum C, Charumanee S, Sivamaruthi BS, Chaiyasut C, Sirithunyalug J, et al. Development of colorectal-targeted dietary supplement tablets containing natural purple rice bran oil as a colorectal chemopreventive. Nutrients 2018; 10: 444. https://doi.org/10.3390/nu10040444

[27] Tuntipopipat S, Muangnoi C, Failla ML. Anti-inflammatory activities of extracts of Thai spices and herbs with lipopolysaccharide-activated RAW 264.7 murine macrophages. J Med Food 2009; 12: 1213-20. https://doi.org/10.1089/jmf.2009.1118

[28] Jomha NM, Elliott JAW, Law GK, McGann LE. Evaluation of condrocyte survival in situ using WST-1 and membrane integrity stains. Cell Tissue Bank 2006; 8: 179-86. https://doi.org/10.1007/s10561-006-9028-6

[29] Irakli MN, Katsantonis DN, Ward S. Rice bran: a promising natural antioxidant component in breadmaking. $J$ Nutraceuticals Food Sci 2017; 2: 1-3.

[30] Wu SJ, Liu PL, Ng LT. Tocotrienol-rich fraction of palm oil exhibits anti-inflammatory property by suppressing the expression of inflammatory mediators in human monocytic cells. Mol Nutr Food Res 2008; 52: 921-9. https://doi.org/10.1002/mnfr.200700418

[31] Choi SP, Kim SP, Kang MY, Nam SH, Friedman M. Protective effects of black rice bran against chemicallyinduced inflammation of mouse skin. J Agric Food Chem 2010; 58: 10007-15. https://doi.org/10.1021/jf102224b

[32] Ju J, Picinich SC, Yang Z, Zhao Y, Suh N, Kong AN, et al. Cancer-preventive activities of tocopherols and tocotrienols. Carcinogenesis 2010; 31: 533-42. https://doi.org/10.1093/carcin/bgp205

[33] Shin SY, Kim HW, Jang HH, Hwang YJ, Choe JS, Lim Y, et al. gamma-Oryzanol-rich black rice bran extract enhances the innate immune response. J Med Food 2017; 20: 855-63. https://doi.org/10.1089/jmf.2017.3966

[34] Rao YPC, Sugasini D, Lokesh BR. Dietary gamma oryzanol plays a significant role in the anti-inflammatory activity of rice bran oil by decreasing pro-inflammatory mediators secreted by peritoneal macrophages of rats. Biochem Biophys Res Commun 2016; 479: 747-52. https://doi.org/10.1016/j.bbrc.2016.09.140

Received on 15-04-2019

\section{DOI: https://doi.org/10.29169/1927-5951.2019.09.04.2}

(C) 2019 Pattananandecha et al.; Licensee SET Publisher.

This is an open access article licensed under the terms of the Creative Commons Attribution Non-Commercial License (http://creativecommons.org/licenses/by-nc/3.0/) which permits unrestricted, non-commercial use, distribution and reproduction in any medium, provided the work is properly cited. 